\title{
Creep Structure Effect of Layered Rock Mass Based on Acoustic Emission Characteristics
}

\author{
Huichen Xu $\mathbb{D}^{1,2}$ Yong Zhang $\mathbb{D}^{2,3}$ Chengwei Zhao, ${ }^{2,3}$ Chengyu Miao, ${ }^{2,3}$ \\ and Xiaoming Sun $\mathbb{1}^{2}$ \\ ${ }^{1}$ College of Mechanical and Architectural Engineering, Taishan University, Taian, Shandong 271000, China \\ ${ }^{2}$ State Key Laboratory for Geomechanics and Deep Underground Engineering, China University of Mining and Technology, \\ Beijing 100083, China \\ ${ }^{3}$ School of Mechanics and Civil Engineering, China University of Mining \& Technology, Beijing 100083, China
}

Correspondence should be addressed to Xiaoming Sun; sunxiaoming@cumtb.edu.cn

Received 3 May 2021; Revised 14 June 2021; Accepted 24 August 2021; Published 15 September 2021

Academic Editor: Jiang Jin

Copyright $\odot 2021$ Huichen Xu et al. This is an open access article distributed under the Creative Commons Attribution License, which permits unrestricted use, distribution, and reproduction in any medium, provided the original work is properly cited.

\begin{abstract}
Investigating the creep structural effect of layered rock mass is of great practical and theoretical significance. In this paper, taking the Muzhailing tunnel as an example, structure effect of layered rock mass based on acoustic emission characteristics has been analyzed. The study shows that creep parameters of layered rock mass are significantly influenced by structural effects, and the overall creep variable is small. The creep deformation of layered rock mass includes transient creep and steady-state creep at a low stress level. At a higher stress level, when the long-term strength of the rock sample is reached, the deformation increases rapidly, and the accelerated creep occurs in a very short period of time. The creep equation of the structural effects of layered rock mass was established based on the experimental results. Acoustic emission characteristics are analyzed during creep experiment; the study shows that the energy released at the time of initial loading and destruction accounted for most of the total energy. The initial energy release increased first and then decreased with the increase in inclination angle; as the inclination angle increased, the cumulative energy when the rock sample was damaged first decreased and then increased. The structural effect on the main frequency value at the time of failure mainly reflected in the trend that the main frequency value first increased and then decreased as the inclination angle increased. Based on the above analysis, we can recognize the structural effects of layered rock mass and provide the necessary parameters for on-site support.
\end{abstract}

\section{Introduction}

Muzhailing tunnel is a key control project of the Lanzhou-Haikou national expressway $[1,2]$. The tunnel is a part of a large deeply buried highway tunnel with a total length of approximately $15 \mathrm{~km}$, a maximum buried depth of approximately $638 \mathrm{~m}$, and a maximum horizontal principal stress of $24.95 \mathrm{MPa}$. It is located at a high altitude at which construction is difficult, owing to heavy rainfall. The layered rock surrounding the tunnel is shallow metamorphic slate, and fissures of the surrounding rock have been relatively developed. Several rock masses are broken because of the groundwater that mainly arises from fissure water, where the amount of water inflow is large. During the construction process, there are spotted and rainy water. The rock surrounding the site are deformed and intruded by water. The large deformation of the local vault due to the long-term effect of groundwater is shown in Figure 1. The variation in the inclination angle of the layered surrounding rock of the Muzhailing tunnel is diversified. The forms of large deformation and failure caused by different inclination angles are different; this is referred to as the layered rock mass structural effect. While studying the deformation and failure of tunnels, the influence of the structural effects of layered rock mass on the large deformation failure must be considered. The different inclination angles resulting in different deformations and failure are shown in Figure 2.

In the study of the structural effects of the layered rock mass, many scholars have considered the uniaxial compressive strength, tensile strength, and changes of physical 

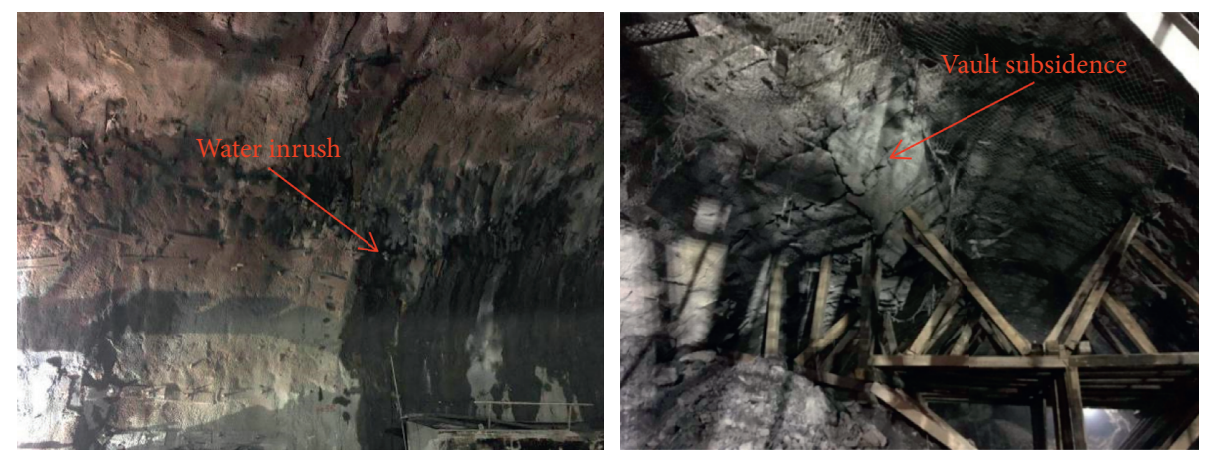

FIGURE 1: Failure characteristics of layered surrounding rocks.
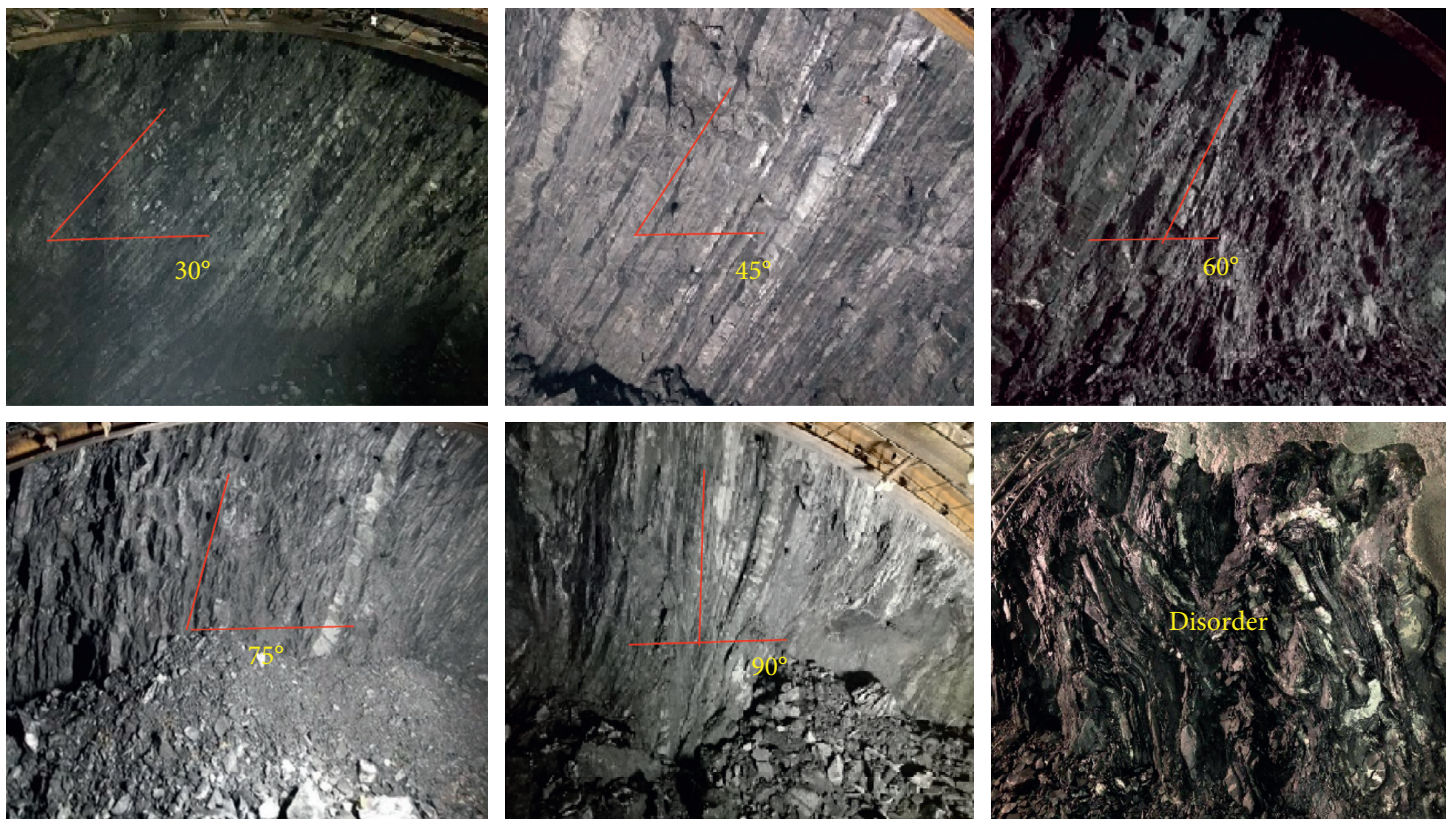

FIGURE 2: Structural effect of layered surrounding rocks of the tunnel.

and mechanical parameters of layered rock masses with different inclination angles [3-9]. Tavallali studied the tensile strength, crack propagation law, and failure energy characteristics of sandy slate with different inclination angles. The results showed that the tensile strength, crack growth, and the required energy consumption gradually decreased with the increase in the inclination angle [10]. Attewell and Sandford [11] studied the influence of structural plane inclination on various parameters using the shear experiment results. Tao and King [12] obtained the relationship between the elastic modulus, Poisson's ratio, and inclination angles by measuring the acoustic wave velocity of rocks. Zhang et al. [13] established five different numerical models of regular sawtooth joints, taking the sawtooth angle a as the variable, to study the shear mechanical characteristics of joints under creep condition. Lin et al. [14] established a nonlinear viscoplastic element on the basis of time-dependent shear strength by connecting the plastic element representing shear strength with the viscous element in parallel. Results showed that the modified Burgers model can reflect the mechanical properties of rock in three creep stages. Lin et al. [15] introduced and established a nonlinear function for describing the time-dependent change of parameters and an improved variableparameter nonlinear Nishihara shear creep model of rocks. The mechanical properties of rocks under the shear creep test condition were studied, and the deformation characteristics and long-term shear strength of rocks during creep were analyzed.

Because of the large buried depth of the Muzhailing tunnel, the rock mass is broken, with considerable change in the inclination angle of layered rock mass. The deformation of the surrounding rock is significantly affected by the structural effects of the layered rock mass. Under the coupling of high geostress and groundwater, the creep characteristics of the surrounding rock of the tunnel are significant. In addition, the large amount of deformation has a serious impact on the tunnel excavation process and construction safety. Therefore, investigating the creep structural effect of layered rock mass is of great practical and theoretical significance. At present, there are only few 
researches on the creep structural effect of layered rock mass based on acoustic emission characteristics.

\section{Geological Background and Experimental Method}

The layered rock samples were collected at the AZK216 + 380-AZK220 + 300 cave sections of the deeply buried Muzhailing tunnel. The Muzhailing tunnel is located in Gansu Province, China, as shown in Figure 3. The engineering geological section of the tunnel is shown in Figure 4 . The rock samples of the cave section were processed with inclination angles of $0^{\circ}, 30^{\circ}, 45^{\circ}, 60^{\circ}$, and $90^{\circ}$, which corresponded to the layered surrounding rock with different inclination angles of $0^{\circ}, 30^{\circ}, 45^{\circ}, 60^{\circ}$, and $90^{\circ}$, respectively, as shown in Figure 5.

2.1. Mineral Composition and Microstructure. Rock samples underwent mineral composition analysis, and the results are shown in Tables 1 and 2. From the results, it can be seen that the rock sample was mainly composed of quartz (49.6\%) and clay minerals $(47.9 \%)$. The clay mineral content was high and was mixed with illite, chlorite, and yum. Among the clay minerals were illite $(50 \%)$ and the Illinois/Smectite mixed layer (17\%). The analysis showed that the content of the Illinois/Smectite mixed layer was relatively high and possessed strong water absorption. The volume expanded rapidly after absorbing water, which was easily softened, disintegrated, and expanded, ultimately resulting in a decrease in the strength of the rock.

From Figure 6, which shows the electron microscopic scan of the rock sample, it can be seen that the sample was dense, and the pores were not developed.

2.2. Experimental Process. The experimental study on creep structural effect of layered rock mass used five-axis creep experimental system that consisted of five main components, as shown in Figure 7.

(1) In the main unit, five interconnected independent loading systems are arranged in a line, and each loading system is equipped with an actuator, a bearing plate, a test piece loading ball seat, and a servo control device.

(2) Environmental devices are confining system, hightemperature measurement control system, and pore water (gas) channel.

(3) Power source is power electric start load, uninterruptible power supply with large capacity, gas hydraulic power source, and hydraulic energy storage.

(4) For microcomputer measurement and control devices, each independent loading body is equipped with an axial displacement sensor, a force sensor, a water (gas) pressure sensor, a circumferential extensometer, and a temperature sensor; a data acquisition measurement and control board and a

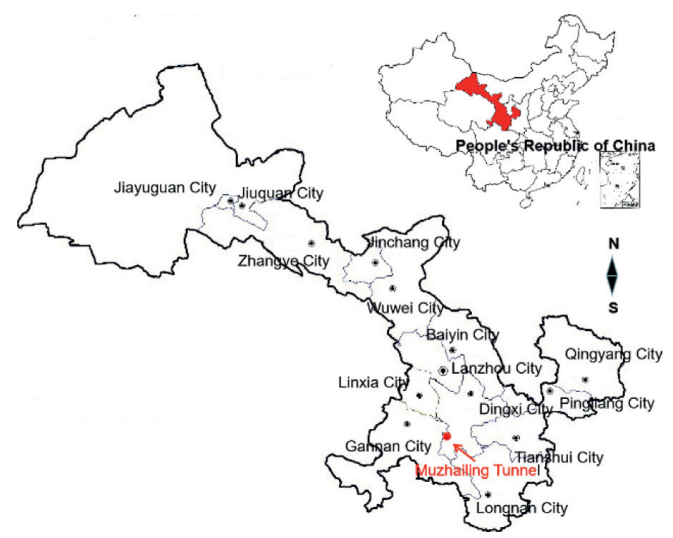

FIGURE 3: Location of the Muzhailing tunnel.

servo drive device; and a microcomputer, a printer, a measurement, and control support software.

Studies have shown that rock creep occurs when the stress level reaches the range between $20 \%$ and $80 \%$ of the instantaneous strength; therefore, the loading stress of each stage should be the uniaxial compressive strength multiplied by the grading factor. To facilitate the analysis of stress creep characteristics, acoustic emission characteristics, and other parameters, the same stress-loading path was adopted in this experiment.

According to the uniaxial compression experiment, the rock sample with inclination angle of $45^{\circ}$ has the lowest uniaxial compressive strength; therefore, the uniaxial compressive strength of the $45^{\circ}$ inclination angle was selected as the instantaneous strength standard. The first stage load to the fourth stage load was $20 \% \sigma c, 40 \% \sigma c, 60 \%$ $\sigma c$, and $80 \% \sigma c$, respectively. However, the classification coefficient $80 \% \sigma \mathrm{c}$ is too small and can hardly reach the failure strength for the other inclination angle. Therefore, the fifth load to the seventh load are designed to be $100 \%$ $\sigma c, 120 \% \sigma c$, and $140 \% \sigma c$ for the other inclination angle samples. The design of the loading path is shown in Figure 8.

\section{Results and Analysis}

3.1. Analysis of Stress-Time Results. The stress-time curve results of the creep experiments on rock samples with different inclination angles are shown in Figure 9. The longterm strengths of the rock sample with inclination angles of $0^{\circ}, 30^{\circ}, 45^{\circ}, 60^{\circ}$, and $90^{\circ}$ were $72 \mathrm{MPa}, 65 \mathrm{MPa}, 48 \mathrm{MPa}$, $48 \mathrm{MPa}$, and $72 \mathrm{MPa}$, respectively, which are smaller than the UCS at the same inclination angle, respectively. When the failure occurred, and the time at which the failure occurred was $123.3 \mathrm{~h}, 119.8 \mathrm{~h}, 71.9 \mathrm{~h}, 71.9 \mathrm{~h}$, and $122.3 \mathrm{~h}$, respectively. This indicated that, as the inclination angle increased, the long-term creep strength decreased first before increasing.

Images of failed rock samples are shown in Figure 10. The figure shows that mixed destroyed including shearing failure and tensile failure occurred for the rock sample at the inclination angle $0^{\circ}$. Shearing failure of rock samples 


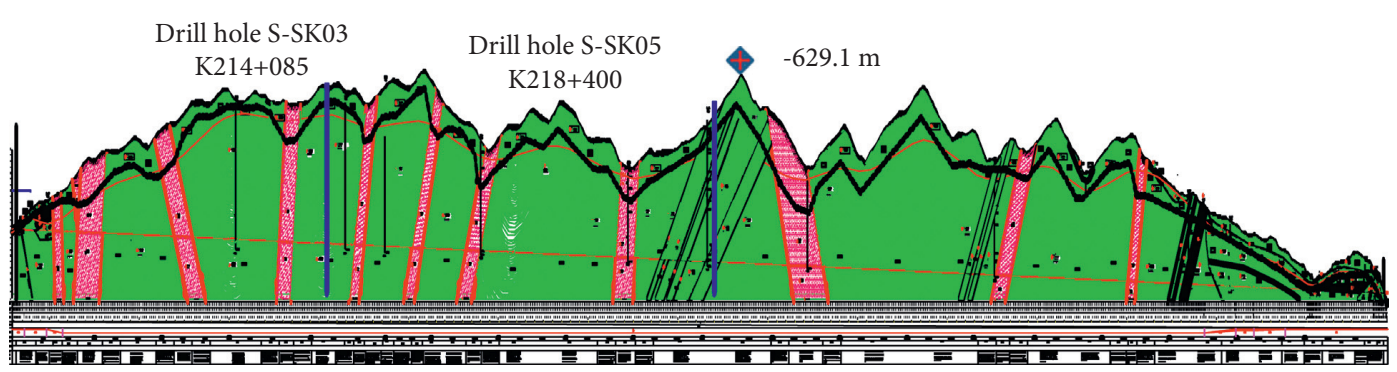

FIGURE 4: Engineering geological section of Muzhailing tunnel.

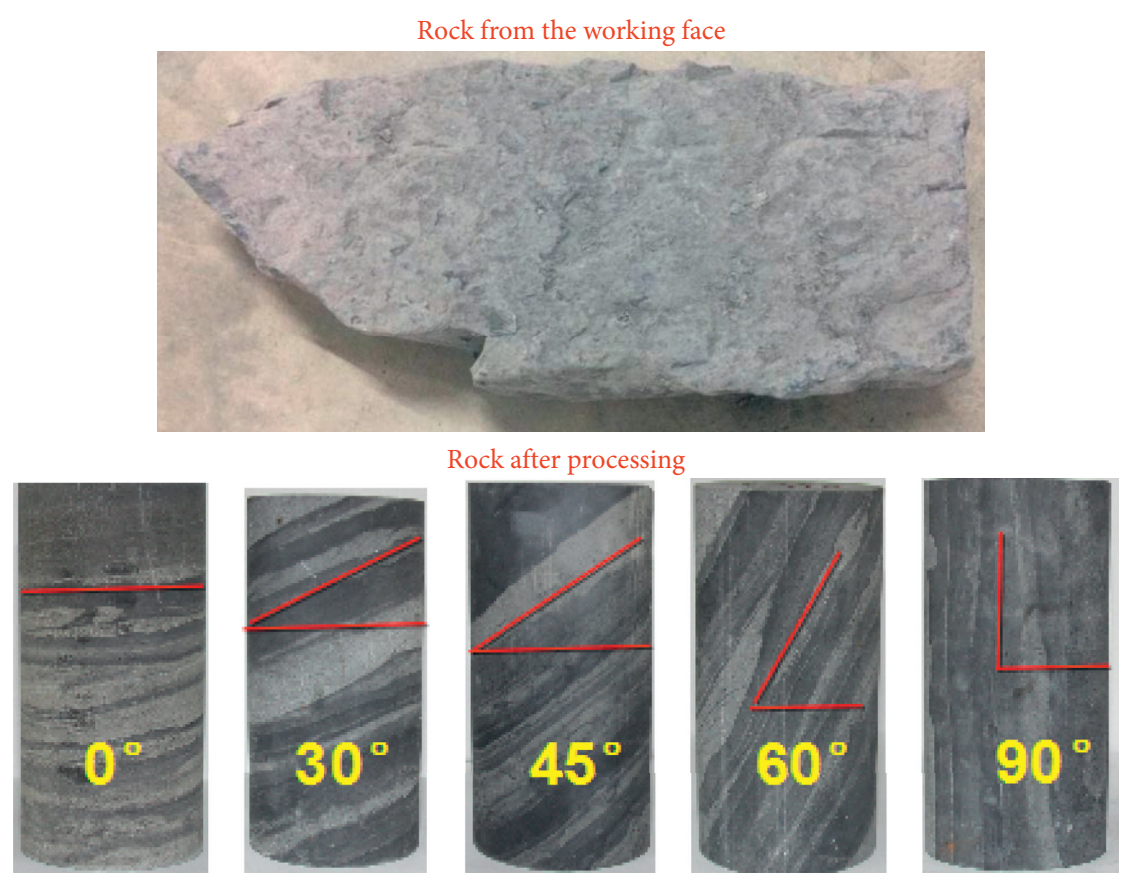

Figure 5: Processing of rock samples.

TABLE 1: Analysis of mineral diffraction of slate.

\begin{tabular}{lcccc}
\hline No. & & \multicolumn{3}{c}{ Mineral content (\%) } \\
& Quartz & K-feldspar & Plagioclase & Clay mineral \\
\hline Sample 1 & 43.8 & 1.0 & 2.2 & 53.0 \\
Sample 2 & 48.1 & - & - & 51.9 \\
Sample 3 & 50.9 & 0.9 & 1.8 & 46.4 \\
\hline
\end{tabular}

TABLE 2: Relative content of clay mineral.

\begin{tabular}{lccccccc}
\hline \multirow{2}{*}{ No. } & \multicolumn{4}{c}{ Clay mineral relative content (\%) } & \multicolumn{2}{c}{ Mixed layer ratio (\%) } \\
& S & I/S & I & K & C & Py & I/S \\
\hline Sample 1 & - & 16 & 44 & 10 & 25 & 5 & 10 \\
Sample 2 & 3 & 16 & 47 & 9 & 25 & - & 5 \\
Sample 3 & - & 22 & 42 & 13 & 18 & 5 & 10 \\
\hline
\end{tabular}

S: Smectite; I: Illite; I/S: Illite/Smectite formation; K: Kaolinite; C: Chlorite; Py: pyrophyllite. 

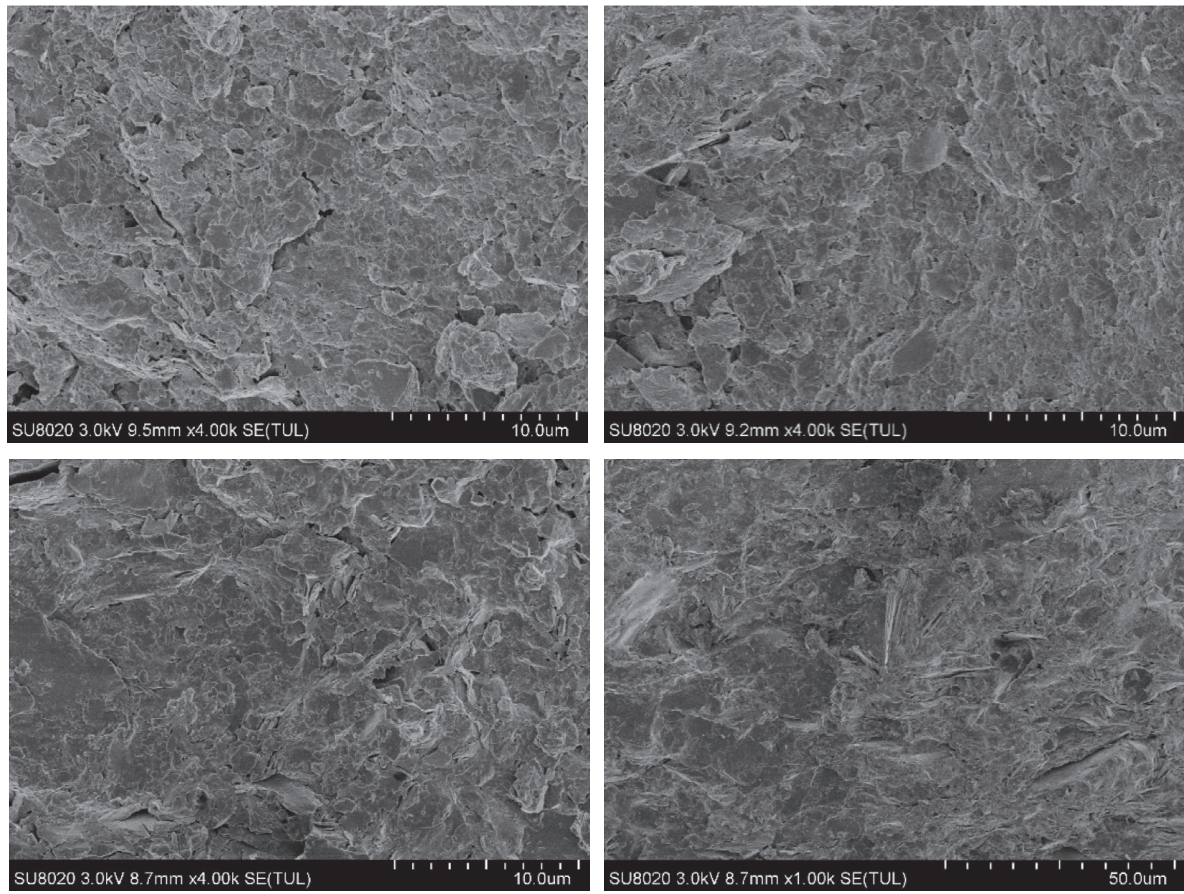

FIGURE 6: SEM image near the beddings for slate of right side.

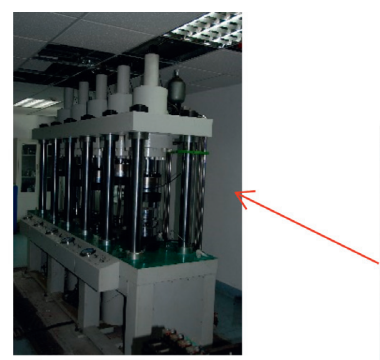

Main unit
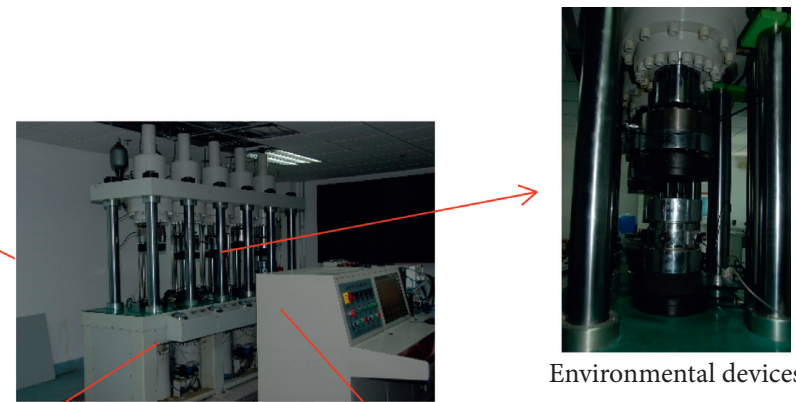

Environmental devices

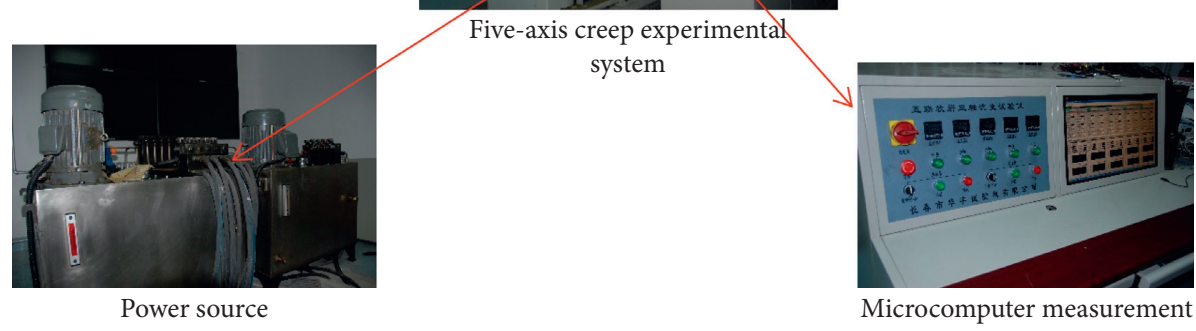

FIGURE 7: Main structure of five-axis creep experimental system.

occurred at inclination angles $30^{\circ}, 45^{\circ}$, and $60^{\circ}$, and tensile failure for rock samples occurred at an inclination of $90^{\circ}$.

3.2. Analysis of Strain-Time Results. The strain-time curve results of rock samples for different inclination angles are shown in Figure 11, from which we can analyze the results considering the following aspects.

3.2.1. Analysis of Creep Time of Rock Samples. While analyzing the total creep time of the rock samples with different inclination angles under different stress levels, it was found that the rock samples with inclination angles of $45^{\circ}$ and $60^{\circ}$ were relatively short. For an inclination angle of $45^{\circ}$, the duration from the initial loading to final destruction of the rock sample was $72.0 \mathrm{~h}$, whereas rock samples with inclination angles of $0^{\circ}$ and $90^{\circ}$ required longer time.

3.2.2. Analysis of Instantaneous Creep Strains of Rock Samples. Rock samples with different inclination angles produced different instantaneous strains, and the largest instantaneous strain occurred at the initial loading stress and was a result of the samples containing primary pores, 


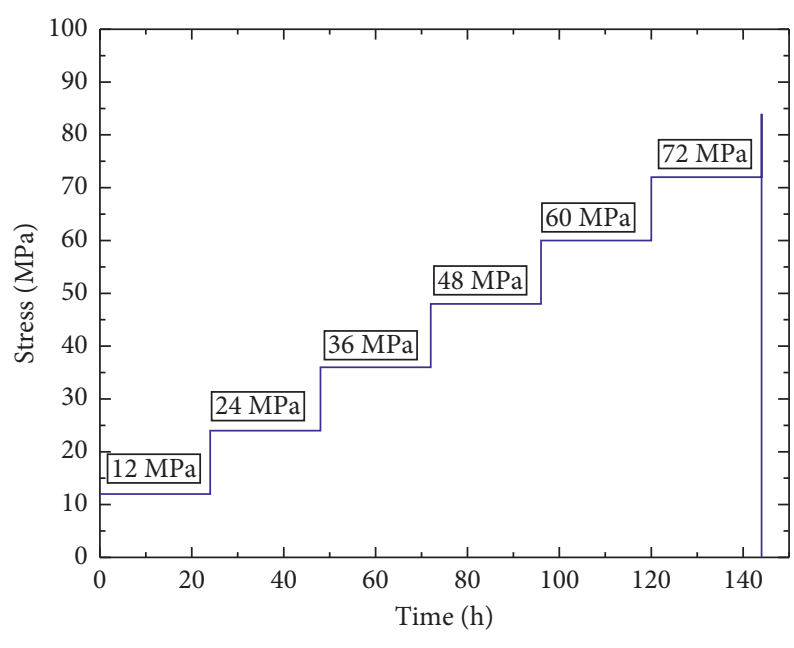

_ Stress Path

Figure 8: Design of the stress path.

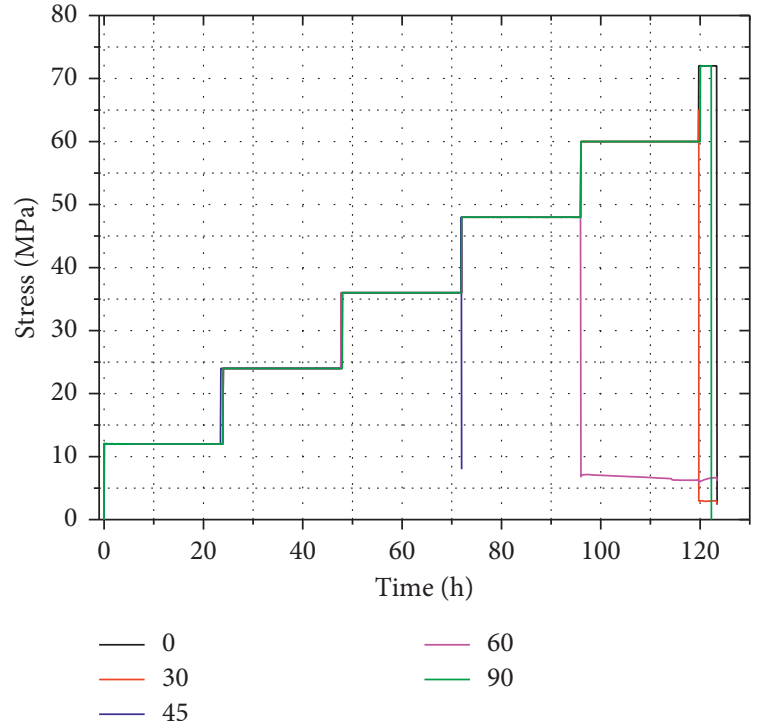

(a)

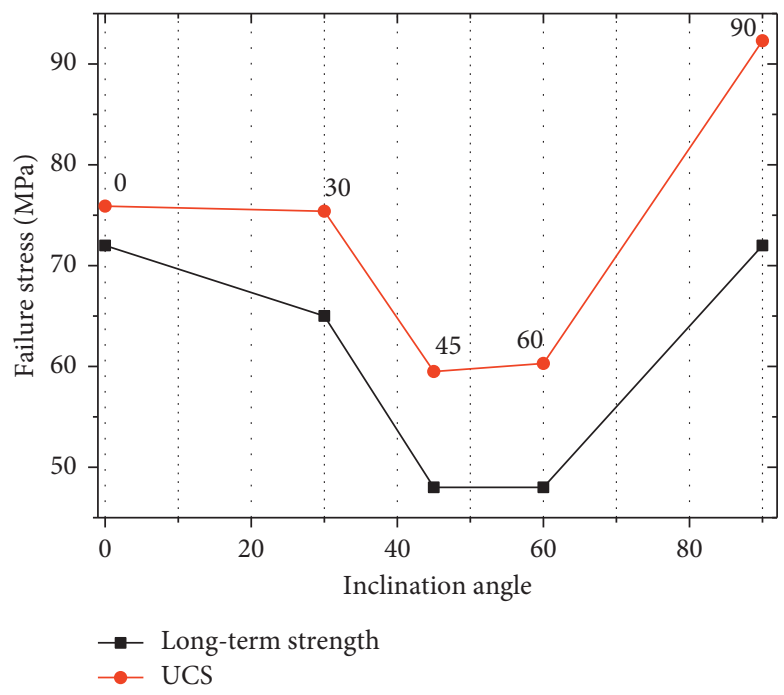

(b)

FIGURE 9: Stress-time curve for different inclination angles.

fissures, and compacted mineral particles. The instantaneous creep strains decreased with increase in the stress level.

3.2.3. Comparison of Instantaneous Elastic Modulus of Rock Samples. The ratio of the increase in the stress level of each stage to the instantaneous strain increase under the current stress level was considered as the instantaneous elastic modulus of the current stress level. The instantaneous elastic modulus of the rock samples at different stress levels is shown in Table 3, and it increased with an increase in the stress level. When the stress level was small, the rate at which the elastic modulus increased was greater, and the elastic modulus increased slowly with an increase in the stress level. While comparing rock samples at different inclination angles, under the same stress level, the instantaneous elastic modulus tended to increase with an increase in the inclination angle. This is because as the inclination angle increased, the loading direction was gradually parallel to the layer direction. The degree of compaction of the rock sample gradually decreased, indicating a decrease in the instantaneous strain and an increase in the elastic modulus.

3.2.4. Comparison of Creep Strain of Rock Samples. The creep process of a rock sample was divided into instantaneous strain and creep strain. Figure 12 shows the trend of the creep strain with the inclination angle under the stress level of each level. The creep strain is small, approximately between $0.002 \%$ and $0.014 \%$. The creep strain of rock 


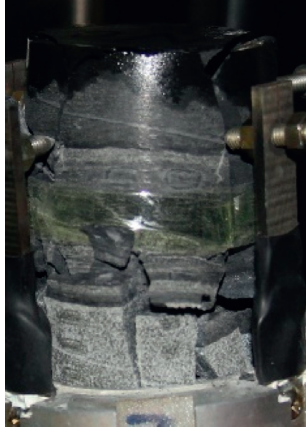

(a)

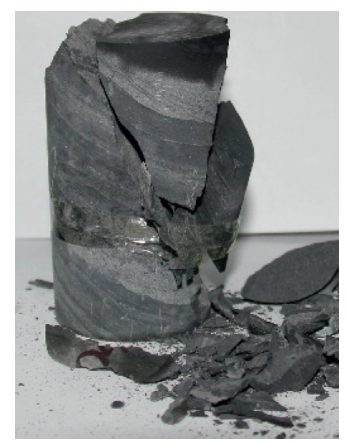

(b)

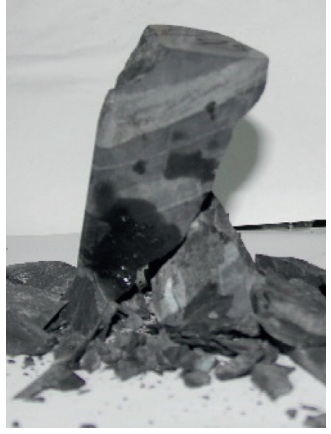

(c)

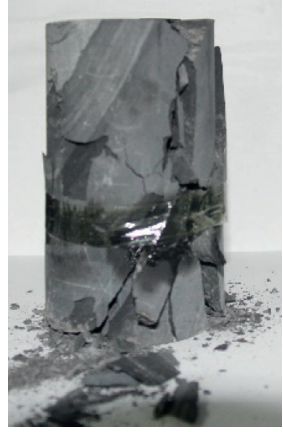

(d)

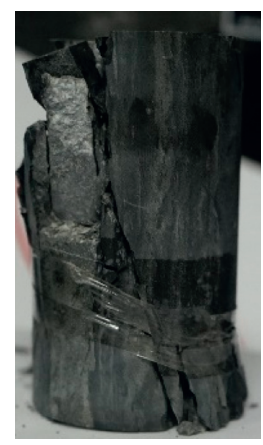

(e)

FIGURE 10: Images of failed rock samples at different bedding angles under natural state. (a) $0^{\circ}$, (b) $30^{\circ}$, (c) $45^{\circ}$, (d) $60^{\circ}$, and (e) $90^{\circ}$.

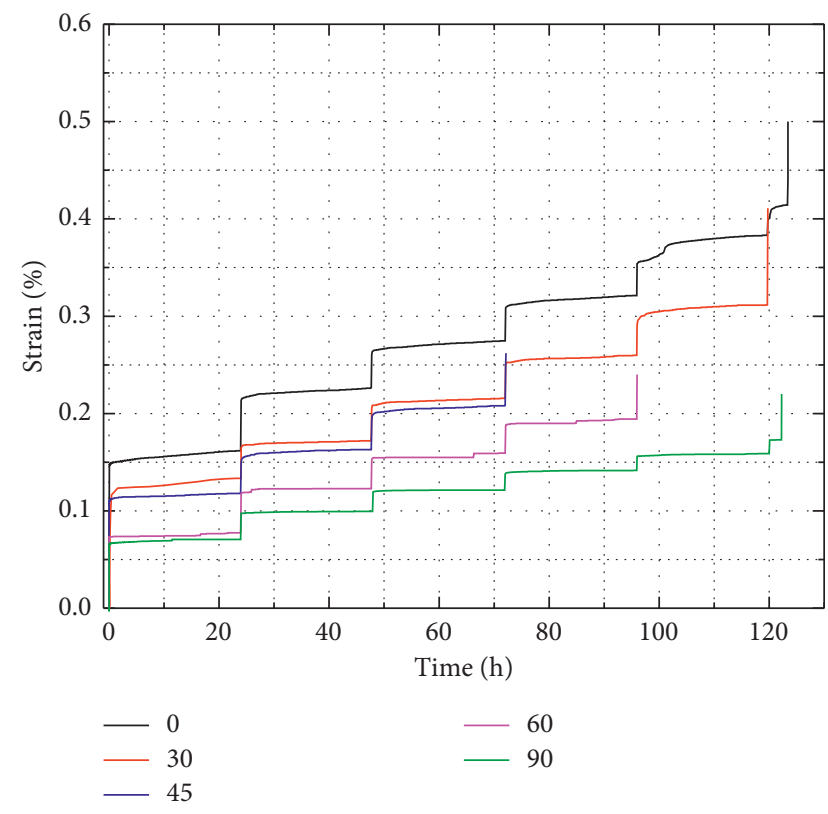

FIGURE 11: Strain-time curve for different inclination angles.

TABLE 3: Instantaneous elastic modulus of rock samples at different stress levels.

\begin{tabular}{lcccccc}
\hline Angle & $12 \mathrm{MPa}$ & $24 \mathrm{MPa}$ & $36 \mathrm{MPa}$ & $48 \mathrm{MPa}$ & $60 \mathrm{MPa}$ & $72 \mathrm{MPa}$ \\
\hline 0 & 8.1 & 23.1 & 35.2 & 35.2 & 35.2 & 39.1 \\
30 & 9.9 & 36.4 & 33.3 & 32.4 & 32.5 & - \\
45 & 10.8 & 35.3 & 40 & - & - & - \\
60 & 16.5 & 30.0 & 37.5 & 41.4 & - & - \\
90 & 18.2 & 44.4 & 60 & 75 & 76.9 & 77.8 \\
\hline
\end{tabular}

samples under the same stress level gradually decreased with the increase in inclination angle.

\section{Analysis and Discussion}

(1) The long-term creep strength of slate is slightly lower than the uniaxial compressive strength of slate with the same inclination angle. As the inclination angle increased, the long-term creep strength decreased first before increasing. The value of long-term

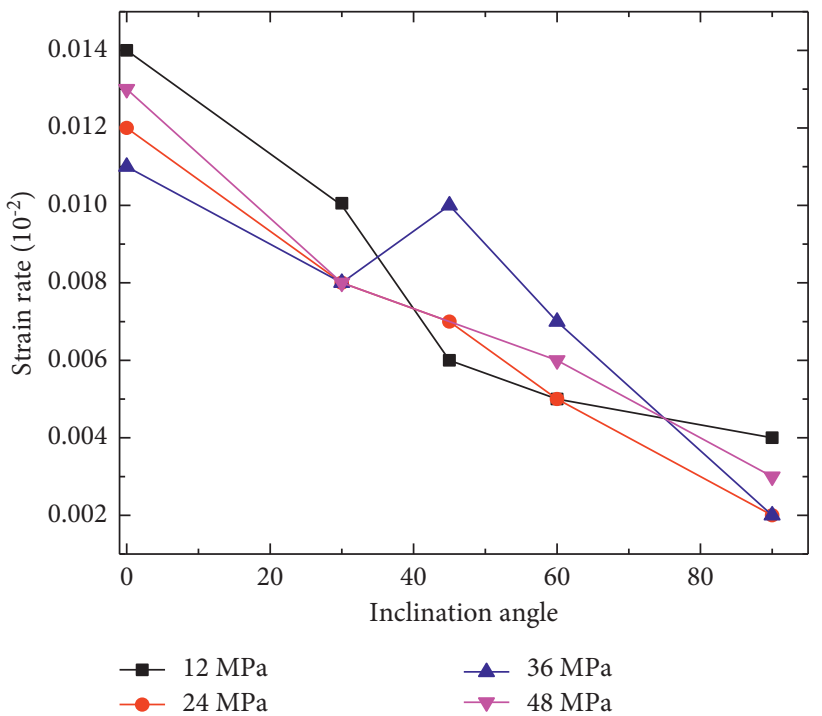

FIGURE 12: Creep strain with inclination angle of the rock sample.

strength of the $0^{\circ}$ inclination angle is the largest. From the point of view of failure characteristics, the $0^{\circ}$ inclination angle rock sample and the $90^{\circ}$ inclination angle rock sample are more severely damaged, and the failure is accompanied by loud noise. $30^{\circ}, 45^{\circ}$, and $60^{\circ}$ inclination angle rock samples are failures along the bedding angle.

(2) The creep deformation of the rock samples under low and medium stress levels was mainly divided into transient creep and steady-state creep, and the creep rate decreased rapidly within $1.5 \mathrm{~h}$ of loading at each stress level. During the steady-state creep stage, the creep rate of the rock samples was stable, low creep rate and small creep variable. At higher stress levels, when the rock sample reached its long-term strength, the deformation increased rapidly, and damage occurred in a very short period. The creep failure process did not significantly accelerate the creep process. At a higher stress level, when the long-term strength of the rock sample is reached, the deformation increases rapidly, and the accelerated creep occurs in a very short period of time. Moreover, it 
exhibited brittle failure characteristics, showing a clear macrofracture surface.

4.1. Constitutive Model. Considering the stress-time and strain-time curve analysis, the creep of layered rock samples with different inclination angles exhibited the following characteristics:

(1) Instantaneous strain occurred at each stress level, and the rock creep model included elastic element response to instantaneous elastic deformation of rock samples.

(2) After the loading stress was stable, the creep strain of the rock sample tended to increase with time. Therefore, the creep model included viscous elements.

(3) When the stress level was low, the creep strain of the rock sample increased slowly, and the creep rate gradually approached 0 .

(4) When the stress level was high, the rock sample was damaged and the accelerated creep phenomenon was not clear.

In summary, the Burgers model reflected the creep properties of layered rock sample more effectively. The Burgers model is a series combination of the Maxwell model and Kelvin model. The Burgers model creep equation is

$$
\varepsilon=\frac{\sigma}{G_{1}}+\frac{\sigma}{\eta_{1}} t+\frac{\sigma}{G_{2}}\left(1-e^{-\left(G_{2} / \eta_{2}\right) t}\right),
$$

where $G_{1}, G_{2}$ are the elastic modulus and $\eta_{1}, \eta_{2}$ are the viscosity coefficients.

The creep model involves more parameters, which makes the parameter determination more complicated. The parameters are analyzed using the least squares method in MATLAB. Because of the large number of rock samples and similar analysis methods, rock samples with an inclination angle of $0^{\circ}$ were selected as the typical rock samples for analysis. At stress level of $12 \mathrm{MPa}$, the values of $\boldsymbol{G}_{\boldsymbol{1}}, \boldsymbol{G}_{\mathbf{2}}, \eta_{\mathbf{1}}$, and $\eta_{2}$ are 56.8, 9.4, 1668.6, and 0.2, respectively, and the correlation coefficients is 0.94 . At stress level of $24 \mathrm{MPa}$, the values of $\boldsymbol{G}_{1}, \boldsymbol{G}_{2}, \eta_{1}$, and $\eta_{2}$ are $14.9,41.8,7018.4$, and 1.5, respectively, and the correlation coefficients is 0.98 . At stress level of $36 \mathrm{MPa}$, the values of $\boldsymbol{G}_{\boldsymbol{1}}, \boldsymbol{G}_{2}, \eta_{\boldsymbol{1}}$, and $\eta_{\mathbf{2}}$ are 17.4, 61.5, 8343.9 , and 3.4, respectively, and the correlation coefficients is 0.99 . The remaining part has the same trend.

To verify the rationality of the model, the origin fitting creep model was used to compare the experimental results with those shown in Figure 13. From the figure, we can see that the experimental results and the creep model results are similar, which verifies that the Burgers model can respond well with the creep model. It can be seen from the fitted results that the value of $\eta_{1}$ was large, and the creep strain rate was small and consistent with the actual situation. $G_{2}$ represented the elastic modulus in the steady-state creep stage, and $\eta_{2}$ represented the viscosity coefficient. From the experimental results, we can see that the instantaneous elastic modulus $G_{1}$ has the greatest effect on the creep characteristics.

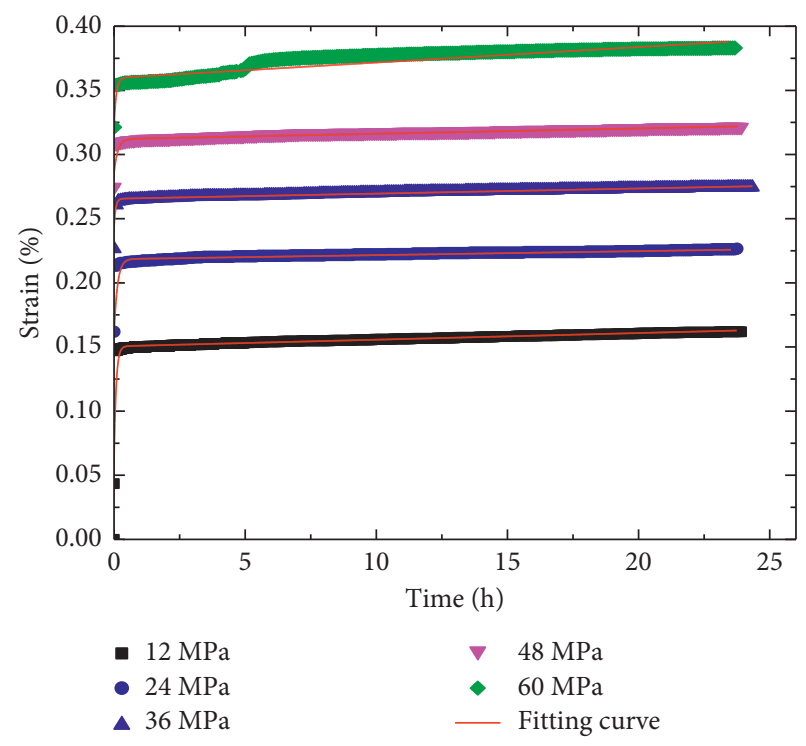

FIGURE 13: Experimental results of creep constitutive model at $0^{\circ}$ inclination angle.

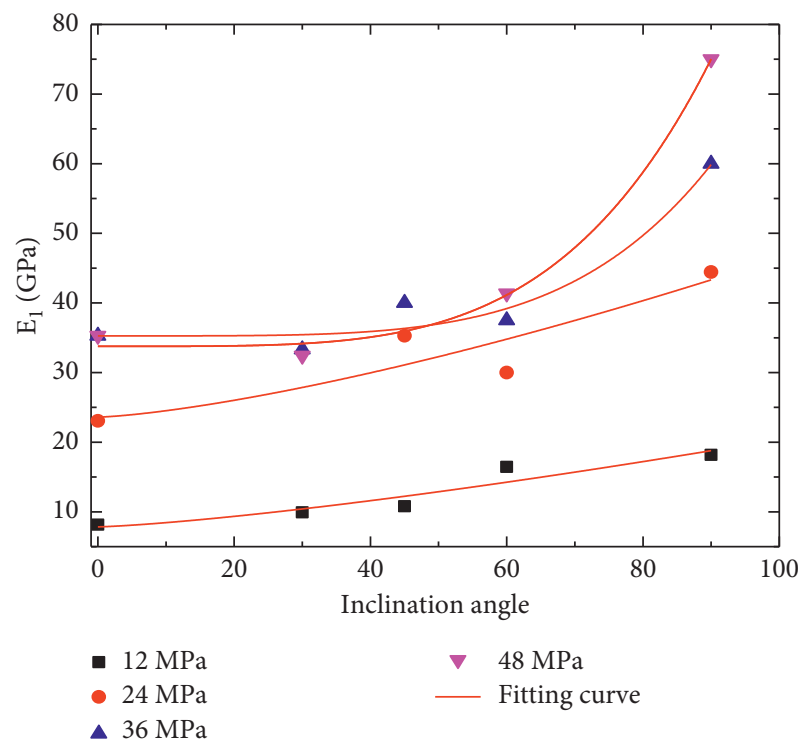

FIgURE 14: Fitting curve of instantaneous elastic modulus at different inclination angles.

The results of creep experiments showed that the creep mechanical properties of layered rock sample were significantly affected by the inclination angle, and the instantaneous elastic modulus had the most significant effect on the creep properties. Therefore, through the fitting relationship between the instantaneous elastic modulus and the inclination angle, the effects of inclination angles were reflected in the creep model. Figure 14 shows the fitting curve of instantaneous elastic modulus at different inclination angles. From the figure, we can see that the instantaneous elastic modulus of the rock sample increases nonlinearly with the inclination angle. The relationship between the instantaneous elastic modulus and inclination angle is expressed as 


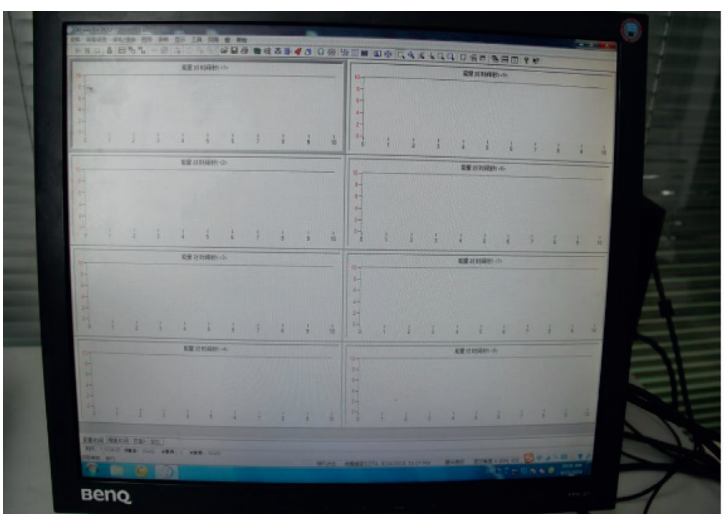

Acquisition systems

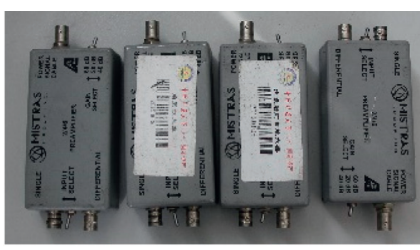

Amplifiers

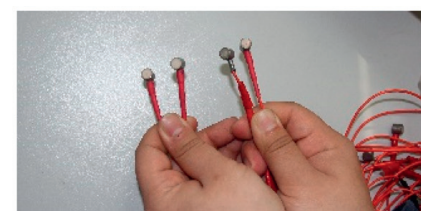

Sensors

Figure 15: Acoustic emission system.

$$
G(\partial)=a \partial^{b}+c
$$

In the equation, a, $b$, and $c$ are fitting parameters, and $\partial$ is inclination angle.

Substitute the values of (2) in (1) to obtain the relationship between the creep equation of layered rock sample and the structural effect:

$$
\varepsilon=\frac{\sigma}{a \partial^{b}+c}+\frac{\sigma}{\eta_{1}} t+\frac{\sigma}{G_{2}}\left(1-e^{-\left(G_{2} / \eta_{2}\right) t}\right) .
$$

\section{Analysis on Acoustic Emission Characteristics}

Acoustic emission can effectively capture the elastic waves in the emergence, closure, development, and penetration of cracks in the rock and can reflect the energy release process during material failure [16]. By processing and analyzing the waveform signals, we can better understand the waveform characteristics of key points during loading and failure of rock samples. It is of great significance to understand the influence of structural effects of layered rock samples.

The acoustic emission in the experiment was performed by the American Physical Acoustics Corporation PCI-2, and the basic parameters considered were a frequency response range of $100 \mathrm{~Hz}-1 \mathrm{MHz}$, a sampling rate of $2 \mathrm{M}$ valid data points per second, and a threshold value of $50 \mathrm{~dB}$. Acoustic emission acquisition systems, amplifiers, and sensors are shown in Figure 15.

The amplitude-frequency-time three-dimensional spectrum was obtained by using fast Fourier transform (FFT) and short-time Fourier transform in MATLAB to analyze the main frequency value. The main frequency value of the waveform signal was inversely proportional to the rupture scale, which implied that high frequency corresponded to small-scale damage and low frequency corresponded to large-scale damage. The FFT is calculated by the following equation [16]:

$$
X(k)=\sum_{i=0}^{N} x(i) e^{-j 2 \pi i k /(N+1)}, \quad k=0,1,2, \ldots, N .
$$

The squared expression of the short-time Fourier transform is

$$
S_{n}(t, f)=\left|\int_{-\infty}^{+\infty} N(t) \eta\left(t_{1}-t\right) e^{-i 2 \pi f t_{1}} \mathrm{~d} t_{1}\right|^{2} .
$$

Figures 16-20 are a plot of parts of stress path, the absolute energy, cumulative energy, and the main frequency value of key points with inclination angles of $0^{\circ}, 30^{\circ}, 45^{\circ}, 60^{\circ}$, and $90^{\circ}$. The rock samples at inclination angles of $0^{\circ}, 30^{\circ}, 45^{\circ}$, $60^{\circ}$, and $90^{\circ}$ were similar to the acoustic emission energy characteristics manifested by the rapid release of instantaneous energy during initial loading. The subsequent cumulative energy of the rock sample released slowly with each loading because only a small number of microcracks and fractures were generated. The cumulative energy surged again when it was eventually destroyed. According to the release characteristics of accumulated energy, $\mathrm{N}_{1}$ and $\mathrm{N}_{2}$ were set as key points to analyze the accumulated energy and the main frequency value.

The cumulative energy of key points $\mathrm{N}_{1}$ and $\mathrm{N}_{2}$ are shown in Figure 21(a), from which we can see that the cumulative energy level of key point $\mathrm{N}_{1}$ at different inclination angles is between $3.9 \mathrm{E} 4$ and 6.6E5; the cumulative energy level of key point $\mathrm{N}_{2}$ is between $2.4 \mathrm{E} 8$ and 1.8E9. The figure shows that the initial energy (at key point $\mathrm{N}_{1}$ ) release increases first and then decreases with the increase of inclination angle; as the inclination increases, the cumulative energy first decreases and then increases when the rock sample is damaged by the initial energy (at key point $\mathrm{N}_{2}$ ); this is because of the coupling effect of the loading time effect and structural effect.

Main frequency values of key point for different inclination angles are shown in Figure 21(a), and the following characteristics were observed after analysis.

(1) The key points $\mathrm{N}_{1}$ to $\mathrm{N}_{2}$ of different rock samples from high to low frequency were significantly reduced; the values of key point $\mathrm{N}_{1}$ were between 310 and $320 \mathrm{kHz}$ in the high frequency range, of which rock samples with inclination angles of $30^{\circ}, 45^{\circ}$, and $90^{\circ}$ had a minimum frequency of at least $310 \mathrm{kHz}$, and inclination angle of $60^{\circ}$ had a maximum 


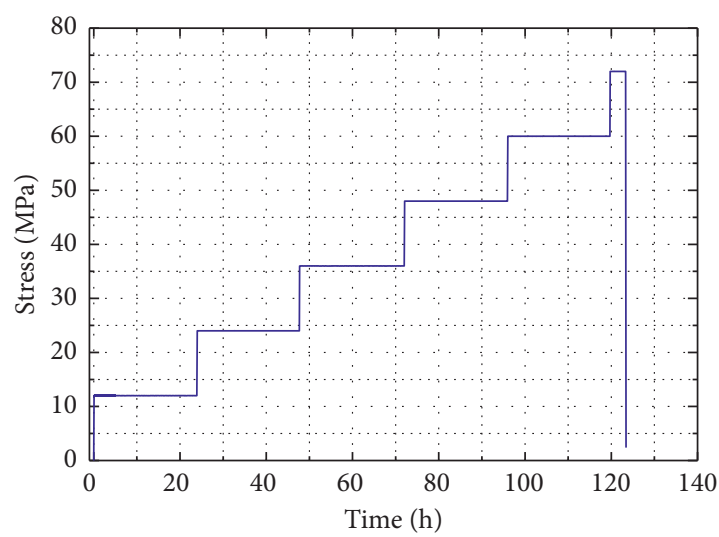

— Stress path

(a)

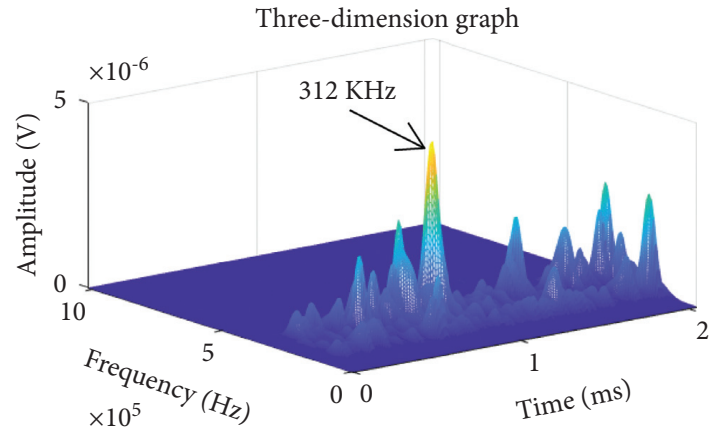

(c)

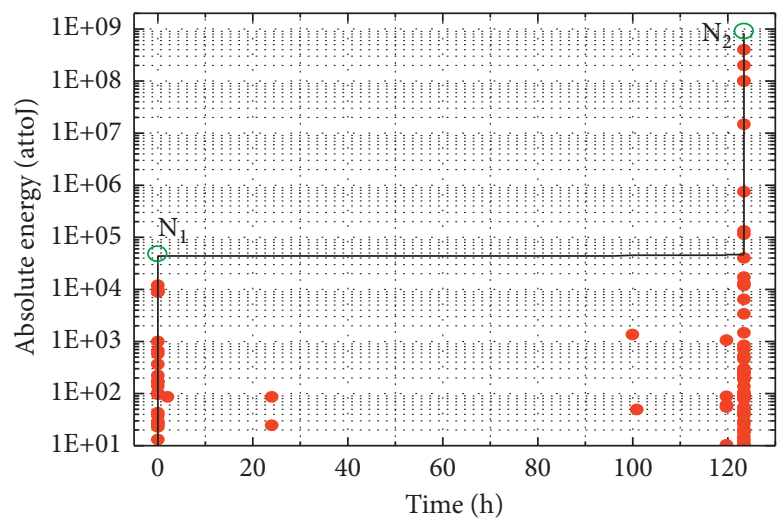

- Absolute energy

- Total absolute energy

(b)

Three-dimension graph

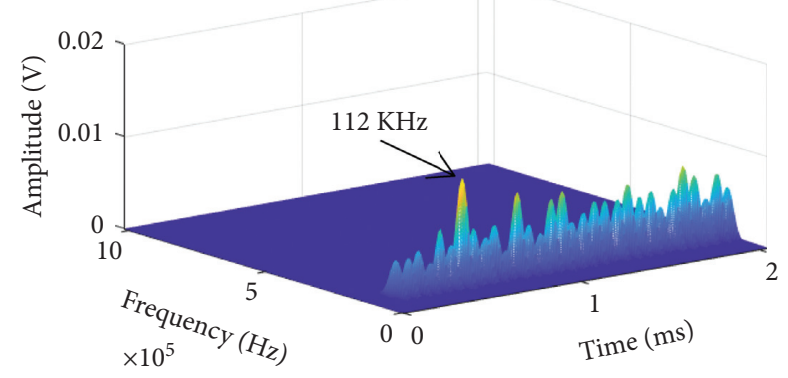

(d)

Figure 16: Result of AE: (a) stress path; (b) absolute energy and (c) total energy; and (d) main frequency value of $\mathrm{N}_{1}$ and $\mathrm{N}_{2}$ for $0^{\circ}$ inclination angles.

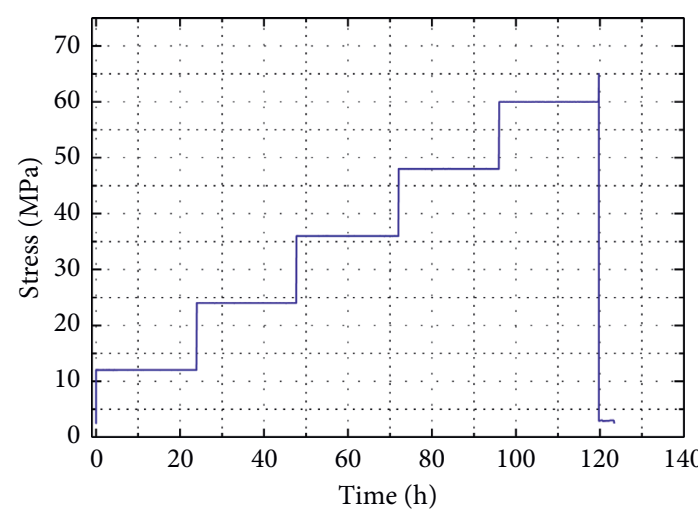

_ Stress path

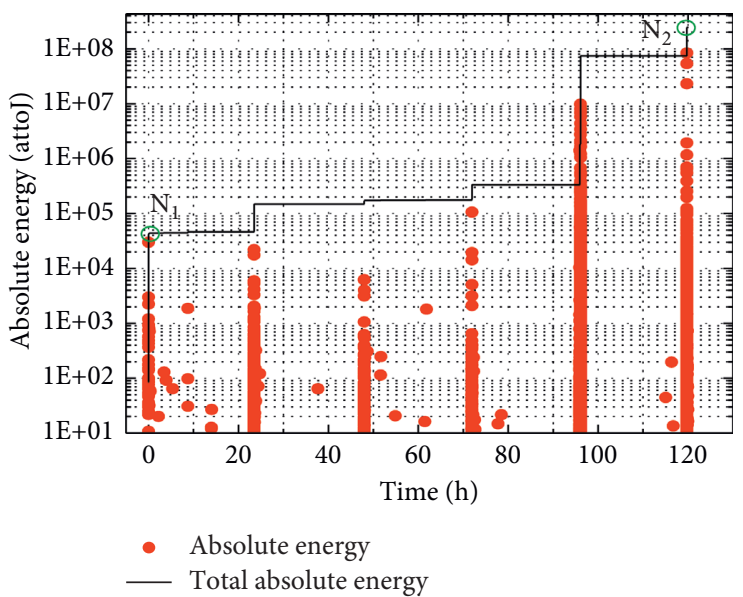

(b)

Figure 17: Continued. 


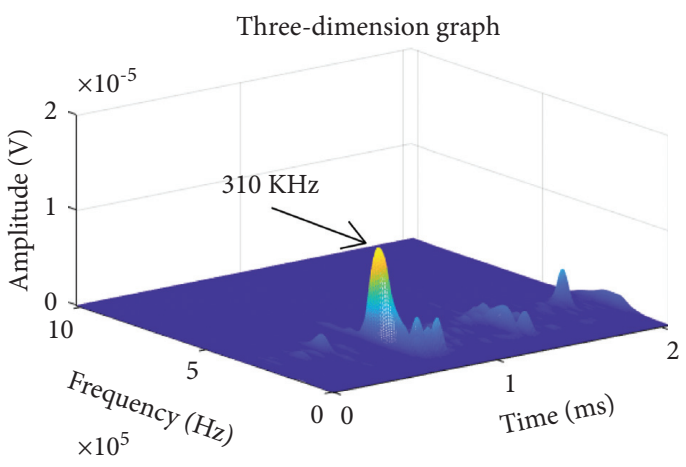

(c)
Three-dimension graph

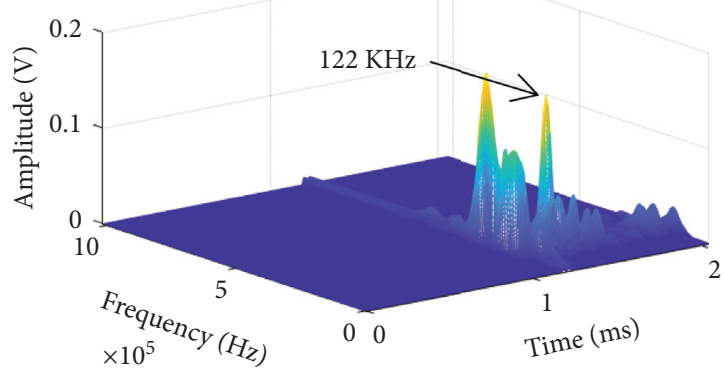

(d)

Figure 17: Result of AE: (a) stress path; (b) absolute energy and (c) total energy; and (d) main frequency value of $\mathrm{N}_{1}$ and $\mathrm{N}_{2}$ for $30^{\circ}$ inclination angles.

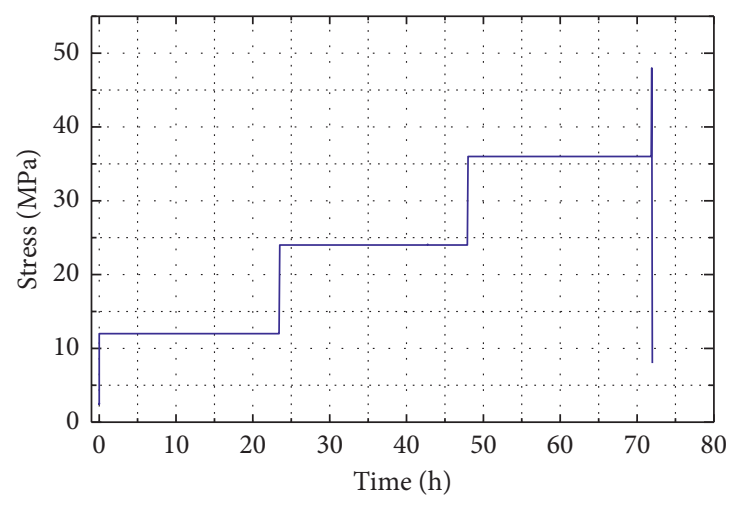

— Stress path

(a)

Three-dimension graph

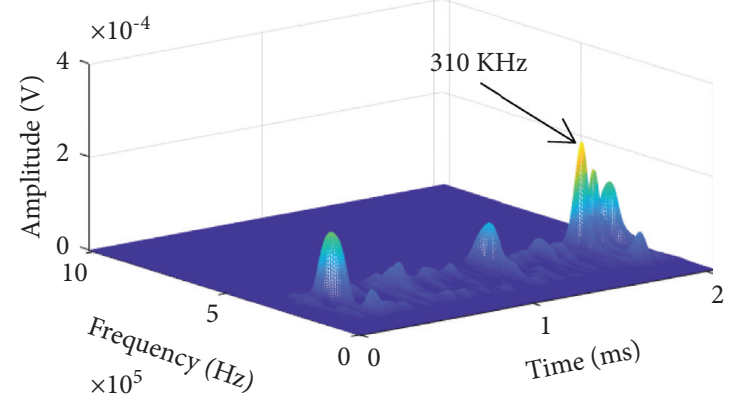

(c)

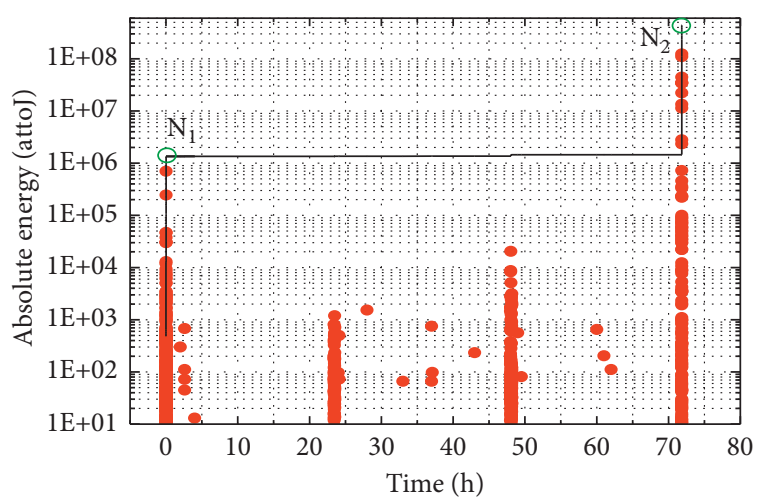

- Absolute energy

- Total absolute energy

(b)

Three-dimension graph

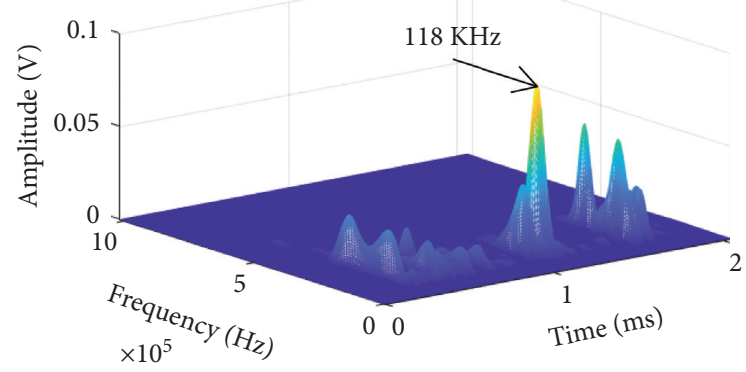

(d)

Figure 18: Result of AE: (a) stress path; (b) absolute energy and (c) total energy; and (d) main frequency value of $\mathrm{N}_{1}$ and $\mathrm{N}_{2}$ for $45^{\circ}$ inclination angles.

frequency of $320 \mathrm{kHz}$; the key point $\mathrm{N}_{2}$ was dominant in the low-frequency range of $105-122 \mathrm{kHz}$. Among them, the main frequency value of the rock samples with $90^{\circ}$ inclination angle was $105 \mathrm{kHz}$, and the highest frequency of $30^{\circ}$ rocks was $122 \mathrm{kHz}$.

(2) The main frequency value at the initial time (key point $\mathrm{N}_{1}$ ) did not get affected by the structural effect significantly. The effect of the structural effect on the main frequency value at the time of failure (key point $\mathrm{N}_{2}$ ) was mainly reflected in the trend that the main frequency value increased first and later decreased as the inclination angle increased.

(3) The key points $N_{1}$ to $N_{2}$ of different inclination angle changed from low amplitude to high amplitude, and the amplitude was increased significantly. 


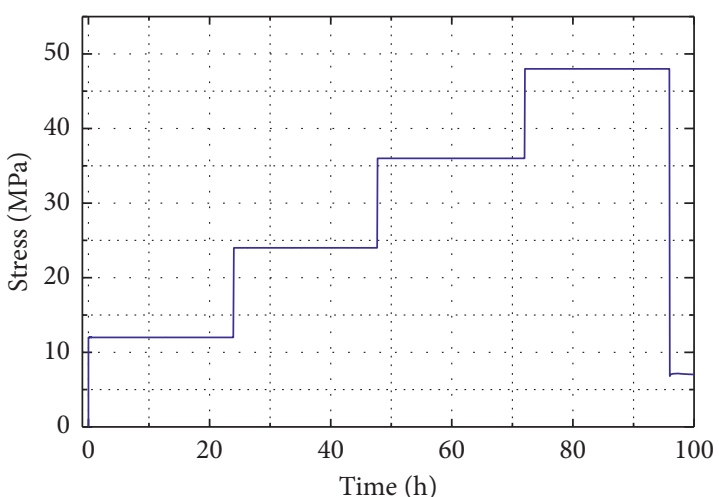

_ Stress path

(a)

Three-dimension graph

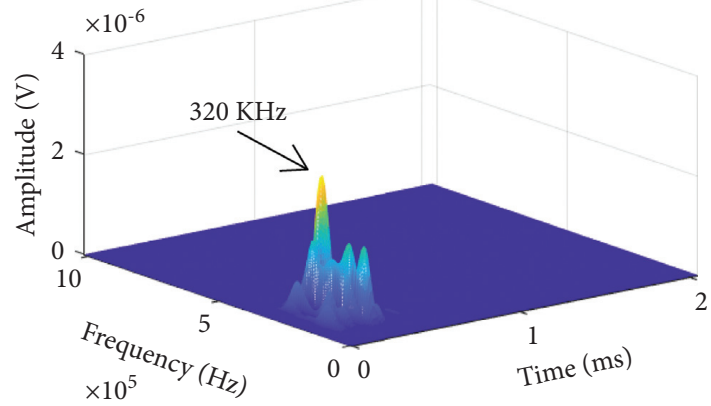

(c)

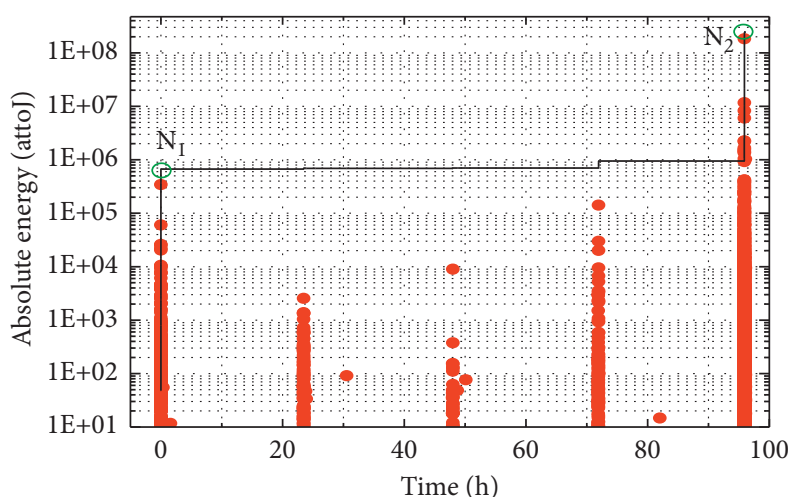

- Absolute energy

Total absolute energy

(b)

Three-dimension graph

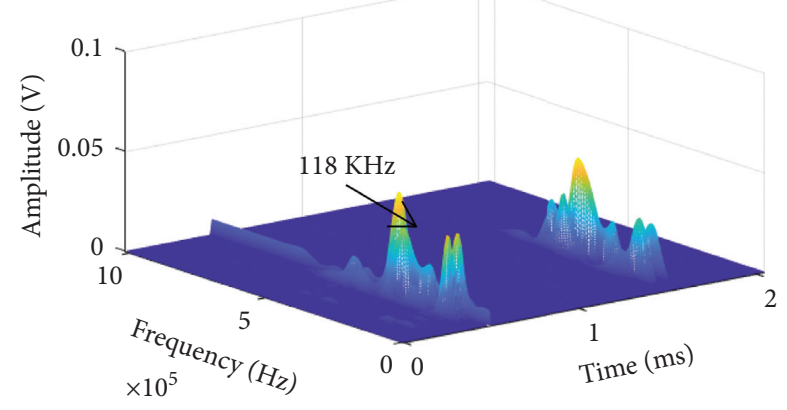

(d)

Figure 19: Result of AE: (a) stress path; (b) absolute energy and (c) total energy; and (d) main frequency value of $\mathrm{N}_{1}$ and $\mathrm{N}_{2}$ for $60^{\circ}$ inclination angles.

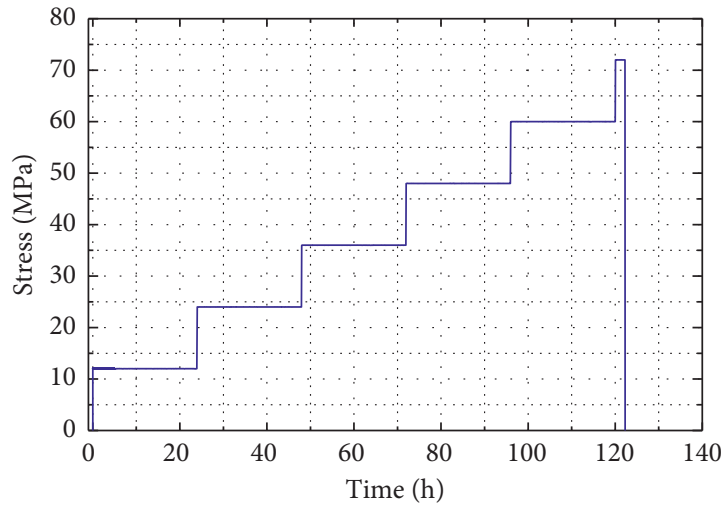

_ Stress path

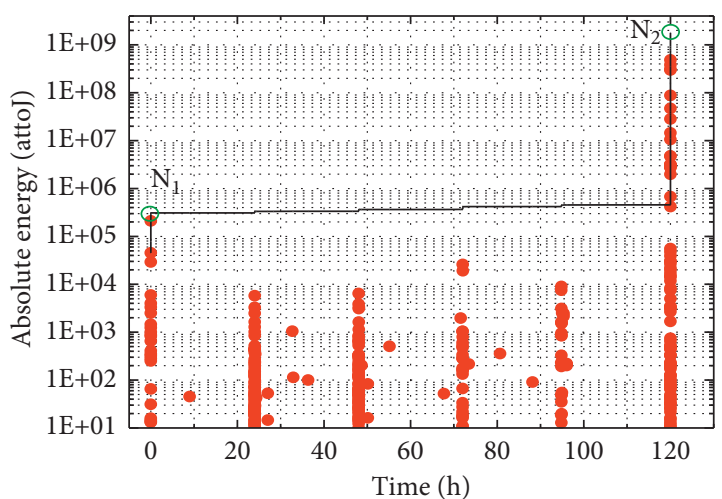

- Absolute energy

- Total absolute energy

(b)

Figure 20: Continued. 
Three-dimension graph

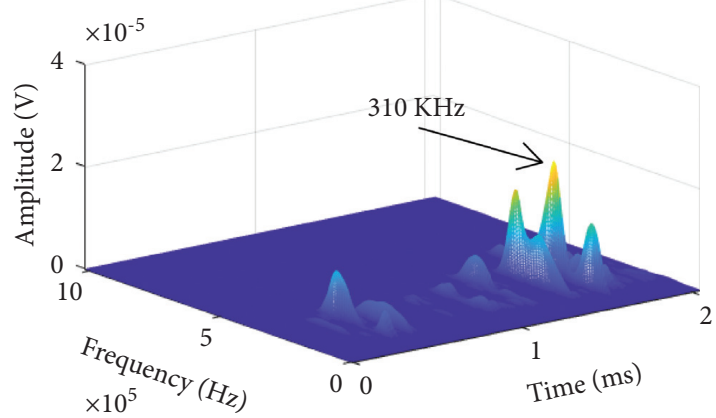

(c)
Three-dimension graph

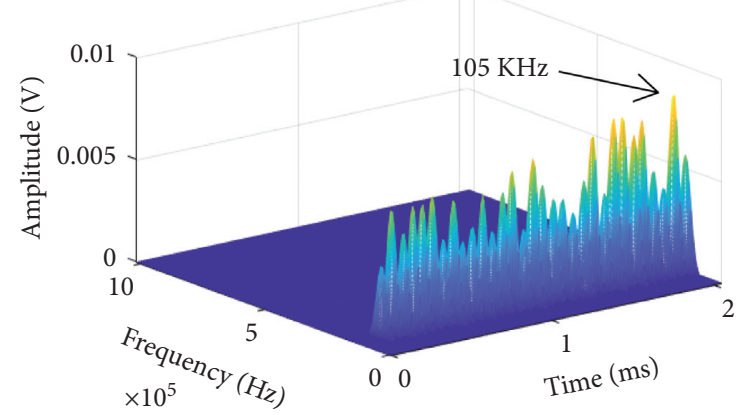

(d)

Figure 20: Result of AE: (a) stress path; (b) absolute energy and (c) total energy; and (d) main frequency value of $\mathrm{N}_{1}$ and $\mathrm{N}_{2}$ for $90^{\circ}$ inclination angles.

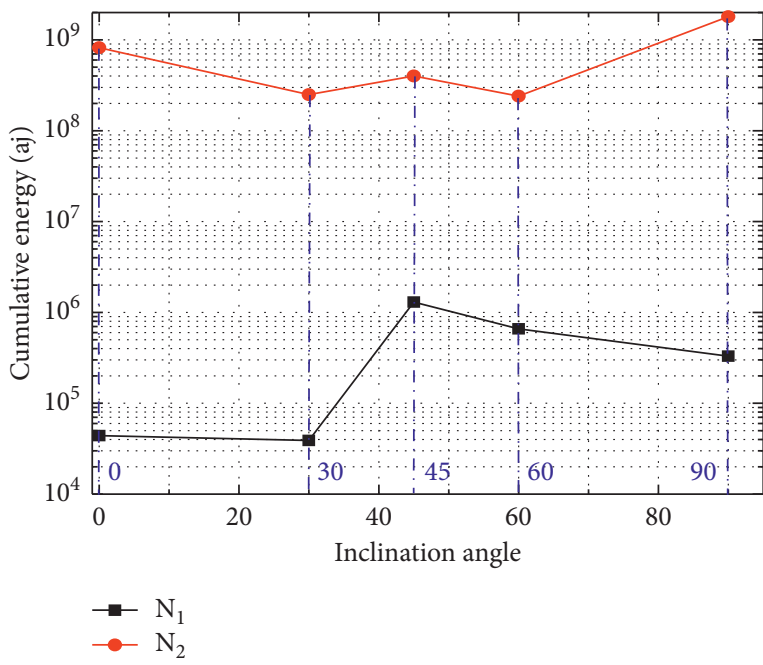

(a)

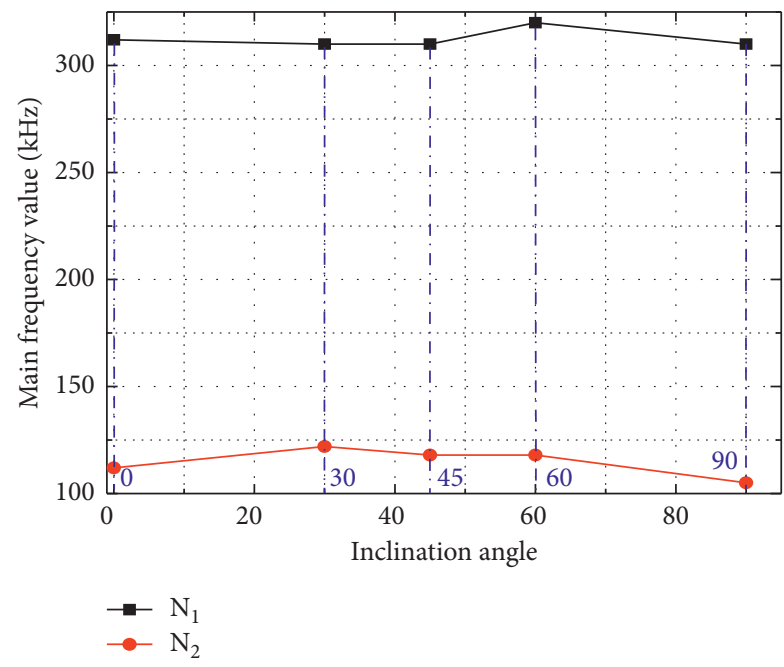

(b)

Figure 21: (a) Cumulative energy with inclination angle and (b) main frequency value with inclination angle.

Based on the field engineering background, the paper studied the structural effects of layered rock masses, established the creep constitutive equation, and analyzed the characteristics of acoustic emission during the experiment. However, layered rock masses are severely affected by groundwater in the field project. Therefore, carrying out research on the creep structure effect of layered rock mass under different water contents is the focus of follow-up research.

\section{Conclusions}

(1) Creep parameters of layered rock mass are significantly influenced by structural effects, and the overall creep variable is small. The creep deformation of layered rock mass includes transient creep and steady-state creep; however, accelerated creep was not clear. The creep equation of the structural effects of rock mass was established based on the experimental results.
(2) The acoustic emission energy released at the time of initial loading and destruction accounted for most of the total energy. The initial energy release increased first and then decreased with the increase in inclination angle; as the inclination angle increased, the cumulative energy when rock sample was damaged first decreased and then increased because of the coupling effect of loading time effect and structural effect.

(3) The main frequency value at the initial time was not significantly affected by the structural effect. The structural effect on the main frequency value at the time of failure mainly reflected in the trend that the main frequency value first increased and then decreased as the inclination angle increased.

\section{Data Availability}

All data generated or analyzed during this study are included in this article. 


\section{Conflicts of Interest}

The authors confirm that there are no known conflicts of interest associated with this publication and there has been no significant financial support for this work that could have influenced its outcome.

\section{Acknowledgments}

This paper was financially supported by the National Key Research and Development Plan of China (Grant no. 2016YFC0600901), the National Natural Science Foundation of China (Grant nos. 51874311 and 51904306), the Yueqi Outstanding Scholar Award Program of China University of Mining and Technology, Beijing, the Special Fund of Basic Research and Operating (Grant no. 2009QL03), and the State Key Laboratory of Open Funds (Grant no. SKLGDUEK1826).

\section{References}

[1] L. I. U. Gao, F. Zhang, L. I. Xinzhao, and C. Yang, "Research on large deformation and its mechanism of Muzhailing tunnel," Chinese Journal of Rock Mechanics and Engineering, vol. 24, no. 2, pp. 5521-5526, 2005.

[2] Y. Wang and Z. Tan, "Structural instability analysis and prevention measures of structural collapse in Muzhailing slate tunnel," Rock and Soil Mechanics, vol. 33, no. 2, pp. 263-268, 2012.

[3] M.-li Xiao, Z. H. U. O. Li, X. I. E. Hong-qiang, and H. E. Jiang$\mathrm{da}$, "Anisotropic rheological properties of quartz-mica schist under triaxial compression creep test," Rock and Soil Mechanics, vol. 36, no. 2, pp. 73-78, 2015.

[4] L. Xiong, L. Yang, and Y. Zhang, "Anisotropic creep test of greenchist under uniaxial compression," Journal of Tongji Universtiy (Natural science), vol. 38, no. 11, pp. 1568-1574, 2010.

[5] C. Wu, Z. Shi, Y. Fu, L. Yang, and Q. Li, "Experimental investigations on structural anisotropy on creep of greenschist," Chinese Journal of Rock Mechanics and Engineering, vol. 33, no. 3, pp. p493-499, 2014.

[6] Y. A. N. G. Songlin, J. Zhang, and Q. Huang, "Analysis of creep model of jointed rock," Rock and Soil Mechanics, vol. 25, no. 8, pp. P1125-P1128, 2004.

[7] G. Han, S. Wang, X. Zhang, Y. Wang, G. Zhao, and C. Ma, "Study of creep properties of thinly laminated rock under step loading," Chinese Journal of Rock Mechanics and Engineering, vol. 29, no. 11, pp. 2239-2247, 2010.

[8] P. Xu and S. Yang, "Numerical analysis of creep mechanical property for bedded composite rock," Journal of Mining and Safety Engineering, vol. 35, no. 1, pp. 179-187, 2018.

[9] U. Kuila, D. N. Dewhurst, A. F. Siggins, and M. D. Raven, "Stress anisotropy and velocity anisotropy in low porosity shale," Tectonophysics, vol. 503, no. 1, pp. 34-44, 2011.

[10] A. Tavallali and A. Vervoort, "Failure of layered sandstone under Brazilian test conditions: effect of micro-scale parameters on macro-scale behaviour," Rock Mechanics and Rock Engineering, vol. 43, no. 5, pp. 641-653, 2010.

[11] P. B. Attewell and M. R. Sandford, "Intrinsic shear strength of a brittle, anisotropic rock-I: experimental and mechanical interpretation," International Journal of Rock Mechanics and Mining Science \& Geomechanics Abstracts, vol. 11, no. 11, pp. 423-430, 1974.
[12] G. Tao and M. S. King, "Shear-wave velocity and anisotropy in rocks: a laboratory study," International Journal of Rock Mechanics and Mining Science \& Geomechanics Abstracts, vol. 27, no. 5, pp. 353-361, 1990.

[13] X. Zhang, H. Lin, Y. Wang, R. Yong, Y. Zhao, and S. Du, "Damage evolution characteristics of saw-tooth joint under shear creep condition," International Journal of Damage Mechanics, vol. 30, no. 3, pp. 453-480, 2021.

[14] H. Lin, X. Zhang, R. Cao, and Z. Wen, "Improved nonlinear Burgers shear creep model based on the time-dependent shear strength for rock," Environmental Earth Sciences, vol. 79, no. 6, p. 149, 2020.

[15] H. Lin, X. Zhang, Y. Wang et al., "Improved nonlinear Nishihara shear creep model with variable parameters for rock-like materials," Advances in Civil Engineering, vol. 2020, pp. 1-15, 2020.

[16] F. Zhao, "Experimental study of important influencing factors for strain rockburst," China University of Mining and Technology, Beijing, China, Doctoral thesis, 2015, https:// oversea.cnki.net/KCMS/detail/detail.aspx?dbcode=CDFD\&d bname $=$ CDFDLAST2016\&filename $=1015444984 . n h \& v=$ dgjf 6v40lZUj7ypRxwEb8\%25mmd2FOulNJpvjuzn4\%25mmd2Ba bV9RpfMF5jZJRFGBjb\%25mmd2FfUQYCwgQC. 